Full Length Research Article

\title{
Effect of Azadirachta indica leaf extract on serum lipid profile changes in normal and streptozotocin induced diabetic rats
}

\author{
R.R. Chattopadhyay ${ }^{\star}$ and M. Bandyopadhyay** \\ *Agricultural Sciences Unit, Indian Statistical Institute, 203, Barrackpore Trunk Road, Kolkata - 700 108, \\ India. \\ ${ }^{* *}$ Department of Pharmacology, School of Tropical Medicine, Kolkata - 700 073, India
}

Received: September, 2004

Accepted: April, 2005

\begin{abstract}
Effects of Azadirachta indica leaf extract on serum lipid profile changes in normal and streptozotocin induced diabetic rats have been studied with a view to elucidate its possible effect on cardiovascular disease induced by hyperglycemia. It was observed that $A$. indica leaf extract significantly reduced the total cholesterol, LDL- and VLDL-cholesterol, triglycerides and total lipids of serum in streptozotocininduced diabetic rats but HDL-cholesterol levels remained unchanged when compared with streptozotocin- induced diabetic control animals.
\end{abstract}

Key words:

Azadirachta indica; Streptozotocin induced diabetes; Serum lipid profiles; cardiovascular disease.

\section{INTRODUCTION}

Diabetes is one of the major degenerative disease in the world today. It is a major risk factor for the development of cardiovascular disease. About 70$80 \%$ of deaths in diabetic patients are due to vascular disease. In particular, hyperglycemia, the primary clinical manifestation of diabetes, is thought to contribute to diabetic complications by altering vascular cellular metabolism, vascular matrix molecules and circulating lipoproteins. For instance hyperglycemia increases diacylglycerol levels and activates protein kinase C activity in the aorta of streptozotocin (stz.) induced diabetic rats (Inoguchi et al, 1994)) and dogs (Xia P et al, 1994). Thickening of the basement membranes in renal glomeruli and peripheral capillaries has been observed in stz. induced diabetic rats (Olgemoller et al, 1993) and hyperlipidemia is a feature of drug induced diabetes in rats (Still et al, 1964) and rabbits (Nordestgaard et al, 1988; Miller and Wilson, 1984).

Many minor components of foods, such as secondary plant metabolites, have been shown to alter biological processes which may reduce the risk of chronic diseases in humans. Azadirachta indica (Meliaceae) popularly known as neem is an indigenous plant widely available in India and Burma. Different parts of this plant have been reported to have antiseptic, wound healing and skin disease curing activity (Kirtikar and Basu, 1975; Biswas et al, 2002). Studies conducted in our laboratory reveals that water soluble portion of alcoholic extract of leaves of Azadirachta indica possesses significant antiinflammatory, antiserotonin, antifertility and hepatoprotective activity (Chattopadhyay R.R.et al, 1987a, 1986, 1993, 1992). Significant hypolipidemic activity in rats fed on atherogenic diet and antihyperglycemic as well as hypotensive activity have also been repoted by us (Chattopadhyay R.R., 1995, 1997 ; Chattopadhyay R.R. et al, 1987b). Significant blood sugar lowering effect of $A$. indica in alloxan and streptozotocin induced diabetic rats have also been reported by several workers (Dixit et al, 1978; Murty et al, 1978; Pillai et al, 1984; Sukla et al, 1973). It is well documented that cardiovascular disease induced by hyperglycemia is associated with alterations in serum lipid profiles (Laakso $M$, 1996; Steiner G, 1999; Massing et al, 2001). In this study, we investigated the effects of $A$. indica leaf extract on serum lipid profile changes in normal and stz induced diabetic rats with a view to 
finding out its possible effect on cardiovascular disease induced by hyperglycemia.

\section{MATERIALS AND METHODS}

Collection of plant material: Fresh Matured leaves of $A$. indica were collected from our Institute's (Indian Statistical Institute, Kolkata, India) garden and were identified by a pharmacognosy expert. At the time of collection standard herbariunm record sheets were completed with the name of the collector, collection number, date, locality and local name.

\section{Extraction of plant material:}

Air-dried powder $(1 \mathrm{~kg})$ of fresh matured $A$. indica leaves were extracted by percolation at room temperature with $70 \% \mathrm{EtOH}$. Leaf extract of $A$. indica was concentrated under reduced pressure (bath temp. $50^{\circ} \mathrm{C}$ ) and finally dried in a vacuum desiccator. The residue was dissolved in distilled water and filtered. The filtrate was evaporated to dryness. The dried mass (yield $=50.2 \mathrm{~g}$ ) was suitably diluted with normal saline and used in experiments.

Animals: Male albino rats of Wistar strain (100$150 \mathrm{~g}$; 4-6 weeks old) were maintained under controlled conditions of light $(12 \mathrm{~h} / 24 \mathrm{~h})$ and teperature $\left(23 \pm 1^{\circ} \mathrm{C}\right)$. Food pellets (Hindustan Lever Ltd., India) and tap water were provided ad libitum .

Development of induced diabetes and assessment of changes in serum lipid profile: Following four groups of rats, six rats in each group were taken.

Group I : Normal Control

Group II: Stz. induced diabetic control

Group III: Stz. induced diabetic Control + A. indica

Group IV: Normal rats treated with $A$. indicaleaf extract

Diabetes was induced in Grp II and Grp. III animals by intraperitoneal injection of streptozotocin (50 mg/kg body weight) dissolved in $0.01 \mathrm{M}$ citrate buffer $(\mathrm{pH} 4.5) .72 \mathrm{~h}$ after streptozotocin injection diabetes was confirmed in rats showing blood sugar level $262 \pm 17 \mathrm{mg} / \mathrm{dl}$. A.indica leaf extract at a fixed dose $(500 \mathrm{mg} / \mathrm{kg}$, po), which was found to be the working dose from our previous experiments was fed daily to stable hyperglycemic (Gr. III) rats $(72 \mathrm{~h}$ after stz. injection) for 7 days consecutively. The normal control (Gr. I) and stz. induced diabetic control (Gr. II) animals received normal saline in place of leaf extract. Gr.IV animals were treated with $A$. indica leaf extract $(500 \mathrm{mg} / \mathrm{kg}, \mathrm{po})$ alone for consequitive 7 days. Animals from each group were deprived of food overnight but with free access of water before taking the samples of blood. Blood samples were collected at the end of 7 days of $A$. indica treatment from orbital plexus by pricking a needle. Serum was separated quickly for estimation of serum lipid profiles. Total cholesterol, total lipids, and triglycerides of serum were estimated using standard methods (Zlatkis et al, 19533; Folch et al, 1957; Varley, 1988). HDL-cholesterol was determined by phosphotungstate/magnesium method (Burstein et al, 1970). VLDL-cholesterol was calculated as triglycerides $/ 5$ and LDL-cholesterol was calculated by the equation :

\section{$L D L$-cholesterol $=$ Total serum cholesterol $-(H D L+V L D L)$.}

Statistical analysis: Results were statistically analysed by analysis of variance (F-test) and multiple comparison procedure (Woolson, 1987). Significance between the groups were estimated using Student's t-test.

\section{RESULTS}

Table 1 shows the results of total cholesterol, total lipids, triglycerides and fractions of cholesterol of serum of Gr. I, II, III and IV animals. It was observed that the levels of total cholesterol, total lipids, triglycerides and fractions of cholesterol except HDL-cholesterol were significantly higher in case of stz induced hyperglycemic animals (Gr. II) when compared with normal control (Gr. I) animals. On the other hand values of above mentioned serum lipid parameters were near to normal in case of animals receiving both $A$. indica leaf extract and streptozotocin (Gr. III Vs. Gr. II). But HDLcholesterol levels remained unchanged. It was also observed that $A$. indica leaf extract failed to alter the levels of serum lipid profiles significantly of normal rats (Gr. IV Vs. Gr. I).

\section{DISCUSSION}

Premature and extensive atherosclerosis involving renal, peripheral and cardiovascular sites remain major complications of diabetes mellitus. In addition to hyperglycemia, systemic or local elevations in insulin may contribute to aberrant lipid metabolism and vascular wall function (Lyons, 1992).

Since alteration in serum lipid profiles are known in diabetics, which are likely to increase the risk of coronary heart disease (Laakso, 1996; Steiner, 1999; Massing et al, 2001), a reduction in serum lipids, particularly LDL and VLDL fractions and triglycerides levels should be considered as beneficial in the long-term prognosis of these patients. 
Table 1.

Effect of $A$. indica leaf extract on serum lipids in normal and induced diabetic rats

\begin{tabular}{|l|l|l|l|l|l|l|}
\hline \multirow{2}{*}{ Group } & \multicolumn{7}{|c|}{ Serum lipid profiles (mg/dl) } \\
\cline { 2 - 7 } & $\begin{array}{l}\text { Total } \\
\text { Cholesterol }\end{array}$ & $\begin{array}{l}\text { Total } \\
\text { lipids }\end{array}$ & Triglycerides & $\begin{array}{l}\text { HDL } \\
\text { cholesterol }\end{array}$ & $\begin{array}{l}\text { LDL } \\
\text { cholesterol }\end{array}$ & $\begin{array}{l}\text { VLDL } \\
\text { cholesterol }\end{array}$ \\
\hline I & $90.00 \pm 5.17$ & $148 \pm 5.74$ & $112.00 \pm 6.42$ & $24.00 \pm 2.92$ & $44.00 \pm 4.12$ & $22.00 \pm 1.84$ \\
\hline II & $128.00 \pm 6.82^{\mathrm{b}}$ & $187.00 \pm 6.88^{\mathrm{b}}$ & $141.00 \pm 7.34^{\mathrm{a}}$ & $21.00 \pm 2.38$ & $77.00 \pm 5.76^{\mathrm{b}}$ & $29.00 \pm 2.14^{\mathrm{a}}$ \\
\hline III & $94.00 \pm 3.24^{\mathrm{a}}$ & $157.00 \pm 5.47^{\mathrm{d}}$ & $109.00 \pm 6.37^{\mathrm{d}}$ & $24.00 \pm 3.17$ & $47.00 \pm 3.75^{\mathrm{c}}$ & $21.00 \pm 2.06^{\mathrm{c}}$ \\
\hline IV & $92.00 \pm 3.74$ & $146.00 \pm 6.14$ & $110.00 \pm 5.61$ & $23.00 \pm 2.47$ & $46.00 \pm 3.64$ & $22.00 \pm 1.92$ \\
\hline
\end{tabular}

Values are mean of six observations \pm S.E.M.

${ }^{a} P<0.05$ when compared with normal control animals (Gr.Il Vs. Gr. I)

${ }^{b} P<0.01$ when compared with normal control animals (Gr. II Vs.Gr. I)

${ }^{c} P<0.05$ when compared with stz. induced diabetic animals (Gr. III Vs.Gr. II)

${ }^{d} P<0.01$ when compared with stz. induced diabetic animals ( Gr.III Vs.Gr. II)

Gr. IV Vs. Gr. I : Not Significant.

Chemical analysis revealed that A. indica leaf extract contains following six compounds: Quercetin-3-O-B-D-glucoside, Myricetin-3-Orutinoside, Quercetin-3-O-rutinoside, Kaempferol3-O-rutinoside, Kaempferol-3-O-B-D-glucoside, Quercetin-3-O- L-rhamnoside (Chattopadhyay, 1999).

It is presumed that these compounds either wholly or partly may be responsible for antihyperlipidemic activity. Thus, it can be concluded from our findings that the levels of total serum cholesterol, triglycerides, total lipids, VLDL and LDL-cholesterol which are actually raised in diabetes can be lowered with $A$. indica leaf extract. Moreover, its antihyperlipidemic effect could represent a protective mechanism against the development of atherosclerosis.

Thus, $A$. indica leaf extract may be helpful in controlling the development of hyperlipidemia as well as atherosclerosis in diabetic subjects in view of its antihyperlipidemic activity. Further studies both on the extract and/or its chemical constituents are needed to pinpoint the findings. This report may serve as a footstep on this aspect.

Acknowledgement: Authors wish to acknowledge the Head, Agricultural Sciences Unit, Indian Statististical Institute, Kolkata and Prof. G. Podder, Professor and Head, Deptt. of Chemistry, School of Tropical Medicine, Kolkata for their cooperation and help during this work.

\section{REFERENCES :}

Betteridge D.J. (1994): Diabetes dislipidemia. American Journal of Medicine (Suppl. 6A), 96 , 25S$31 \mathrm{~S}$.

Biswas Kausik, Chattopadhyay Ishita, Banerjee Ranjit, Bandyopadhyay Uday. (2002): Biological activities and medicinal properties of neem (Azadirachta indica). Current Science, 82(11), 1336-1345.

Burstein M., Scholnick H.R., Morfin R. (1970): Rapid method for isolation of lipoproteins from human serum by precipitation with polyanions. Journal of Lipid Research, 11 , 583- 595..

Chattopadhyay R.(1993): Effect of Azadirachta indica leaf extract on oestrous cycle of ratsa. Environment and Ecology, 11(4) , 958 - 960.

Chattopadhyay R.R. (1995): Hypolipidemic activity of Azadirachta indica leaf extract in rats. Proceedings of Indian National Science Academy B 61, No. 4, 281284.

Chattopadhyay R.R., Chattopadhyay R.N., Nandy A.K., Podder G., Maitra S.K.(1987a) : Antiinflammatory activity of a fraction of fresh leaves of Azadirachta indica (Beng. Neem) Bulletin of the Calcutta School of Tropical Medicine 35, 6-8.

Chattopadhyay R.R., Chattopadhyay R.N., Nandy A.K, Podder G., Maitra S.K.(1986): Antiserotonin activity of a fraction of fresh leaves of Azadirachta indica (Beng. Neem) Bulletin of the Calcutta School of Tropical Medicine 34, 9-12.

Chattopadhyay R.R. (1997): Effect of hydroalcoholic leaf extract of Azadirachta indica on cardiovascular system. General Pharmacology(Elsevier), 28(3), 449 451.

Chattopadhyay R.R.,(1999): Possible mechanism of antihyperglycemic effect of Azadirachta indica leaf extract : Part V. Journal of Ethnopharmacol (Elsevier) 67, 373-.376.

Chattopadhyay R.R., Chattopadhyay R.N., Nandy A.K., Podder G. and Maitra S.K.(1987b): preliminary reporyt on antihyperglycemic effect of a fraction of fresh leaves of Azadirachta indica (Beng. Neem). Bulletin of the Calcutta School of Tropical Medicine 35, 29 - 35. Chattopadhyay R.R., Sarkar S.K., Ganguly S., Banerjee R.N., Basu T.K. and Mukherjee A . (1992): Hepatoprotective activity of Azadirachta indica leaf extract oagainst partacetamol induced hepatic damage in rats. Indian Journal of Experimental Biology, 30 , 738-740.

Dixit V.P., Sinha R. and Tank R. (1986): Effect of neem seed oil on the blood glucose concentration of normal and alloxan diabetic rats. Journal of Ethnopharcology 17,

95-98.

Folch J., Lees M. and Sloane Stanley G.H..(1957) : A simple method for the isolation and purification of total 
lipids from animals tissues. Journal of Biological Chemistry, 226 : 497 - 509.

Inoguchi T., Xia P., Kunisaki M.., Higashi S., Feener E.P. and King G.L. (1994) : Insulin's effect on protein kinase $\mathrm{C}$ and diacylglycerol induced by diabetes and glucose in vascular tissues American Journal of Physiology, 267 , E369- E379.

Kirtikar K.R. and Basu B.D. (1975): Indian Medicinal Plants (eds. Blatter E, Cains JF, Mhaskar KS) Vivek Bihar, New Delhi, p. 536.

Laakso M. (1996): Lipids and Lipoproteins as risk factors for coronary heart disease in non-insulin dependent diabetes mellitus. Ann. Med. 28, 341-345.

Lyons T.J. (1992): Lipoprotein glycation and its metabolic complications. Diabetes 41, (Suppl. 2) 67 73.

Massing M.W., Sueta C.A., Chowdhury M.., Biggs D.P., Simpson R.J. Jr.( 2001) : Lipid management among coronary artery disease patients in diabetes mellitus or advanced age. American Journal of Cardiology 87: 646-664.

Miller R.A. and Wilson R.B. (1984): Atherosclerosis and myocardial ischemic lesions in alloxan-diabetic rabbits fed a low cholesterol diet. Arterioclerosis 4, 586591.

Murty K.S., Rao D.N., Rao D.K., Murty L.B.G. (1978): A preliminary study on the hypoglycemic and antihyperglycemic effect of Azadirachta indica Indian Journal of Pharmacology 10, 247-250.

Nordestgaard B.G.S., Stender S. and Kjeldsen K. (1988): Reduced artherogenesis in cholesterol-fed diabetic rabbits. Giant lipoprotein do not enter the arterial wall. Arteriosclerosis 8, 421-428.
Olgemoller B. and Schleicher E. (1993): Iterations of glomerular matrix proteins in the pathogenesis of diabetic nephropathy. Clinical Investigation, 71 , S13S19.

Pillai N.R. and Santkumari G. (1984): Hypoglycemic activity of Melia Azadirachta Linn. (Neem). Indian Journal of Medical Research14, 931-933.

Steiner G. (1999): Risk factors for macrovascular disease in type 2 diabetes : Classic lipid abnormalities. Diabetes Care 22 (suppl. 3), C6-C9.

Still W.J.S., Martin J.M. and Gregor W.H. (1964): The effect of alloxan diabetes on experimental atherosclerosis in the rat. Experimental Molecular Pathology 3, 141-147.

Sukla R., Sunil S. and Bhandari C.R. (1973): Preliminary clinincal trials on antidiabetic effects of Azadirachta indica. Medicine and Surgury13, 11-12.

Varley's Practical Clinical Biochemistry (1988): $6^{\text {th }}$ Ed., (edited by Alan H. Gowenlock), Heinemann Medical Books, London; pp. 460-475.

Woolson R.F. (1987): Statistical methods for the Analysis of Biomedical Data Wiley series of probability and mathematical statistics), p. 315-325.

Xia P., Inoguchi T., Kern S., Engerman R.L., Oates P.J., King G.L. (1994): Characterization of the mechanism of the chronic activation of diacylglycerolprotein kinase $\mathrm{C}$ pathway in diabetes and hypergalactosomia. Diabetes 43, 1122 - 1129.

Zlatkis A., Zak B, Biyle A.J. (1953): A new method for the direct determination of serum cholesterol. Journal of Laboratory and Clinical Medicine 41, 486-492.

*Correspondence (e-mai address)l: rabi@isical.ac.in 